\title{
Adaptation of Paramecium caudatum to variable conditions of temperature stress
}

\author{
Alison B. Duncan*, Simon Fellous, Elsa Quillery, Oliver Kaltz \\ Institut des Sciences de l'Evolution (ISEM), UMR 5554, Université Montpellier 2, Place Eugene Bataillon, 34095 Montpellier cedex 05, France
}

Received 19 October 2010; accepted 4 April 2011

\begin{abstract}
The environment is rarely constant and organisms are exposed to spatial and temporal variation that will impact life-histories. It is important to understand how such variation affects the adaptation of organisms to their local environment. We compare the adaptation of populations of the ciliate Paramecium caudatum exposed to constant $\left(23^{\circ} \mathrm{C}\right.$ or $\left.35^{\circ} \mathrm{C}\right)$ and temporally variable temperature environments (random daily fluctuations between $23{ }^{\circ} \mathrm{C}$ or $35{ }^{\circ} \mathrm{C}$ ). Consistent with theory, our experiment shows the evolution of specialists when evolution proceeds in constant environments and generalists when the environment is temporally variable. In addition, we demonstrate costs for specialists of being locally adapted through reduced fitness in novel environments. Conversely, we do not find any costs for generalists, as all populations from variable environments had equal or superior performance to specialists in their own environment. The lack of a cost for generalists is emphasised by the presence of a super generalist that has the highest performance at both assay temperatures.
\end{abstract}

Keywords: Local adaptation; Specialists; Generalists; Temperature variation; Thermal stress

\section{Introduction}

Environmental heterogeneity is considered a universal driver of evolutionary change and adaptation (Levins, 1968; Bell, 1997, 2010). Indeed, in nature, organisms are expected to be adapted to the environment, or environments, they experience most commonly. This manifests itself in the evolution of specialists when organisms are exposed to a mostly constant environment, and generalists when changes in environmental state are frequent (Levins, 1968; Kassen, 2002). Accordingly, evolution in spatially structured, constant environments should generate specialists that maximise fitness in their own environment. However, adaptation in one environment is predicted to arise at a cost expressed as low performance in other environments. This could happen due to antagonistic pleiotropy where genes beneficial in one

\footnotetext{
* Corresponding author.

E-mail address: ali.b.duncan@gmail.com (A.B. Duncan).
}

environment are costly in another. Consequently, evolution of a specialist should result in patterns of local adaptation whereby locally selected residents have a higher fitness than foreign, unselected non-residents (Kawecki and Ebert, 2004).

In contrast, temporally variable environments should select for generalist strategies that enable persistence in all environments encountered. Thus, rather than maximising fitness within environments, selection for generalists should maximise average fitness over all environments. As a result, the fitness of generalists in each single environment may be less than that of respective specialists. This is comparable to a lowrisk "bet-hedging" strategy, minimising the variance in performance between environments and allowing at least some average performance in all environments encountered (Stearns, 2000; Kassen, 2002).

The evolution of generalists depends on various genetic and ecological factors, such as the amount of standing genetic variation in populations and environmental structure (Kassen, 2002). An important aspect of the temporal environment is the frequency of exposure to different environments (Levins, 
1968; Bell, 2010). If frequency of exposure to one environment is common and the other rare, local adaptation to the rare environment may not occur. However, if the rare environment is particularly harsh, adaptation to it may be required to guarantee survival following its occurrence.

Microbial organisms are ideal to study adaptation to a variable environment due to their short generation time, large population sizes and the ability to manipulate their environment in a controlled fashion (Jessup et al., 2004). In this study, we use experimental microcosms to investigate the evolution of specialists and generalists in spatially and temporally variable environments. This experiment is the first to investigate how different frequencies of exposure to different environments influences the evolution of generalists. We cultured experimental populations of the ciliate Paramecium caudatum in two constant temperature environments $\left(23{ }^{\circ} \mathrm{C}\right.$ and $\left.35^{\circ} \mathrm{C}\right)$ and in 4 temporally variable temperature environments, with random daily fluctuations between $23{ }^{\circ} \mathrm{C}$ and $35{ }^{\circ} \mathrm{C}$. These variable environments differed in the frequency of occurrence of temperature stress $\left(35^{\circ} \mathrm{C}\right)$, ranging from rare $(\sim 25 \%$ of the time) to frequent $(\sim 75 \%)$. After 4 months $(30-40$ generations), survival and replication at 23 and $35^{\circ} \mathrm{C}$ were compared among populations from the different treatments. The constant environments should select for specialists. Therefore, we predicted performance of populations tested in their own environment to be superior to performance in foreign constant temperature environments (i.e., local adaptation). The variable environments should select for generalists. Thus, we expected the performance of Paramecium from variable treatments to have intermediate fitness to those evolved in constant environments. Further, we expected performance of Paramecium evolved in the different variable environments to differ in each of the constant assay environments according to the amount of time previously spent at each temperature.

\section{Materials and methods}

\subsection{Study organisms}

P. caudatum is a freshwater ciliate found in still water bodies in the northern hemisphere that feeds on bacteria and detritus within the water column (Wichterman, 1986). Reproduction is predominantly asexual through mitotic division. Under exponential growth conditions, P. caudatum divides $1-3$ times every $24 \mathrm{~h}$ and optimal growth temperatures generally range between 24 and $28{ }^{\circ} \mathrm{C}$ (Wichterman, 1986). There is also evidence of within-species genetic variation in growth and survival at different temperatures (Fels and Kaltz, 2006). In our laboratory, Paramecium are maintained at $23^{\circ} \mathrm{C}$, in a culture medium of dried organic lettuce supplemented with the bacterium Serratia marcescens as food (Nidelet,
2007). Two Paramecium clones were used in this experiment, clone K8 and clone VEN (see (Duncan et al., 2010) for details). Each population in the selection experiment comprised $20 \mathrm{ml}$ from mass cultures of each clone in a $50 \mathrm{ml}$ Falcon tube.

\subsection{Selection experiment}

In a 120-day selection experiment, populations of $P$. caudatum were randomly assigned to one of 6 selection treatments, two constant temperature treatments $\left(23{ }^{\circ} \mathrm{C}\right.$, and $35^{\circ} \mathrm{C} \pm 0.5^{\circ} \mathrm{C}$ ) and four variable temperature treatments (with mean temperatures of $26.2{ }^{\circ} \mathrm{C}, 27.8^{\circ} \mathrm{C}, 30.2{ }^{\circ} \mathrm{C}$ or $32.8^{\circ} \mathrm{C}$ ). These variable temperature environments corresponded to $27 \%$, $40 \%, 60 \%$ and $73 \%$ of time during the experiment spent at $35^{\circ} \mathrm{C}$, respectively. Variable mean temperatures were achieved by randomly changing tubes daily between $23{ }^{\circ} \mathrm{C}$ and $35^{\circ} \mathrm{C}$. Each tube was randomly allocated an individual sequence corresponding to its mean temperature. At weekly intervals, $3 \mathrm{ml}$ of each population was removed and replaced with fresh culture medium containing $50 P$. caudatum from source populations of the same clone kept at $23{ }^{\circ} \mathrm{C}$. Table 1 shows mean population sizes prior to the onset of the experiment. All populations were larger than the 50 individuals added each week, indicating selfsustaining populations even at higher temperatures. The experiment contained a total of 48 replicate populations, with 4 replicates per genotype and treatment $(2$ genotypes $\times 6$ selection treatments $\times 4$ replicate populations). On day 120 of the selection experiment, two 1-ml samples were removed from each population and each transferred to a $1.5 \mathrm{ml}$ Eppendorf tube with $500 \mu \mathrm{l}$ of medium. One sample was placed at $23^{\circ} \mathrm{C}$ and the other at $35^{\circ} \mathrm{C}$ for a $48 \mathrm{~h}$ acclimation period.

\subsection{Adaptation assay}

We phenotyped the division of individual Paramecium, from each replicated population at $23{ }^{\circ} \mathrm{C}$ and $35{ }^{\circ} \mathrm{C}$. Four Paramecium cells were individually isolated from each $1 \mathrm{ml}$ sample that had experienced a $48 \mathrm{~h}$ acclimation period prior to the onset of the experiment. Each individual cell was placed in a $60 \mu \mathrm{l}$ drop of culture medium arranged inside the lids of 24microwell plates (Nunc ${ }^{\mathrm{TM}}$, Fisher Scientific, France). The Paramecium were checked for survival and division 24, 30, 36 and $48 \mathrm{~h}$ after start of the experiment.

\subsection{Statistical analysis}

We used repeated-measures ANOVA to analyse the performance of individual Paramecium at $23{ }^{\circ} \mathrm{C}$ and $35^{\circ} \mathrm{C}$ for $48 \mathrm{~h}$ after onset of the experiment. Performance was measured as the $\log _{2}$ (number of cells +1 ) in each $60 \mu \mathrm{l}$ drop through

Table 1

Mean population sizes for Paramecium populations in each of the selection environments prior to the onset of the experiment ( \pm standard error).

\begin{tabular}{|c|c|c|c|c|c|}
\hline $23^{\circ} \mathrm{C}$ Constant & $26^{\circ} \mathrm{C}$ Variable & $28^{\circ} \mathrm{C}$ Variable & $30^{\circ} \mathrm{C}$ Variable & $32{ }^{\circ} \mathrm{C}$ Variable & $35^{\circ} \mathrm{C}$ Constant \\
\hline $812( \pm 118)$ & $1188( \pm 412)$ & $867( \pm 458)$ & $565( \pm 221)$ & $281( \pm 148)$ & $372( \pm 284)$ \\
\hline
\end{tabular}


time. Selection treatment, assay temperature and time were included in models as fixed factors and host clone, replicate population and assay microwell plate as random factors. Nonsignificant terms were removed from models in a stepwise fashion $(p>0.10)$.

Unlike specialists, generalists are predicted to minimise differences in fitness between environments. To test this hypothesis, we averaged $\log _{2}$ (number of cells +1 ) after $48 \mathrm{~h}$ for each replicate population at $23\left(\bar{x}_{23}{ }^{\circ} \mathrm{C}\right)$ and $35{ }^{\circ} \mathrm{C}\left(\bar{x}_{35}{ }^{\circ} \mathrm{C}\right)$. Following Bell (2010), we calculated the environmental variance as $\operatorname{Var}(\mathrm{E})=1 / 2\left(\bar{x}_{23^{\circ} \mathrm{C}}-\bar{x}_{35^{\circ} \mathrm{C}}\right)^{2}$ for each replicate population. In an ANOVA, we tested for difference in $\operatorname{Var}(\mathrm{E})$ among selection treatments. All analysis was done using JMP 8 (SAS, 2008).

\section{Results}

There was a steady increase in density during the experiment for all populations at $23{ }^{\circ} \mathrm{C}$. In contrast, populations at $35{ }^{\circ} \mathrm{C}$ increased only marginally during the first $24 \mathrm{~h}$ of the experiment before stopping division or death. Time series analysis revealed a significant 3-way interaction between time, assay temperature and selection temperature $\left(F_{5,1190}=2.73\right.$, $p=0.0183$ ). This means that differences in relative performance of populations from the different constant and variable selection treatments, at the two assay temperatures, became apparent over the course of the assay. Paramecium from the $23{ }^{\circ} \mathrm{C}$ constant treatment tended to grow better at $23{ }^{\circ} \mathrm{C}$ than those from the $35^{\circ} \mathrm{C}$ constant treatment. The reverse was true for Paramecium from the $35{ }^{\circ} \mathrm{C}$ treatment, that had greater survival at $35{ }^{\circ} \mathrm{C}$ than Paramecium from the $23{ }^{\circ} \mathrm{C}$ constant treatment. Paramecium from the variable treatments varied in their responses, with their relative ranks depending on the assay temperature and identity of the variable treatment (Fig. 1). The host clone and its interactions were not significant and never explained more than $3.5 \%$ of the variance in the model.

Fig. 2 illustrates general patterns observed during the $48 \mathrm{~h}$ period for Paramecium from the different selection treatments. Crossing of reaction norms for growth of Paramecium from the two constant environments at the two assay temperatures is clearly shown. Performances of Paramecium from populations with variable selection treatments were generally equal to or greater than resident lines from the respective constant treatment. One variable treatment (populations with a mean of $26{ }^{\circ} \mathrm{C}$ ) had the highest performance at both assay temperatures, indicating the presence of a super generalist.

The environmental variance in performance $\operatorname{Var}(\mathrm{E})$ did not significantly differ among selection treatments $\left(F_{5,28}=0.85\right.$, $p=0.5264)$. Thus, there was no evidence that populations from variable (generalist) treatments had reduced variation in performance at 23 and $35^{\circ} \mathrm{C}$ compared to those from constant (specialist) treatments. Fig. 2 illustrates this comparable variation in performance between populations from constant and variable treatments at $23{ }^{\circ} \mathrm{C}$ and $35^{\circ} \mathrm{C}$.

We projected the fitness of Paramecium at variable mean temperatures by combining fitness measured at $23{ }^{\circ} \mathrm{C}$ and at $35{ }^{\circ} \mathrm{C}$. We calculated mean (geometric) fitness of variable generalists and constant specialists at different variable treatment mean temperatures. The geometric mean is a more appropriate measure of fitness across temporally variable environments (Bell, 2010). Fig. 3 shows better fitness of generalists in all variable environments, in particular for increasing mean temperatures, i.e., in environments with more frequent exposure to $35{ }^{\circ} \mathrm{C}$. Some generalists even appear capable of invading constant specialist populations, in
A $23^{\circ} \mathrm{C}$

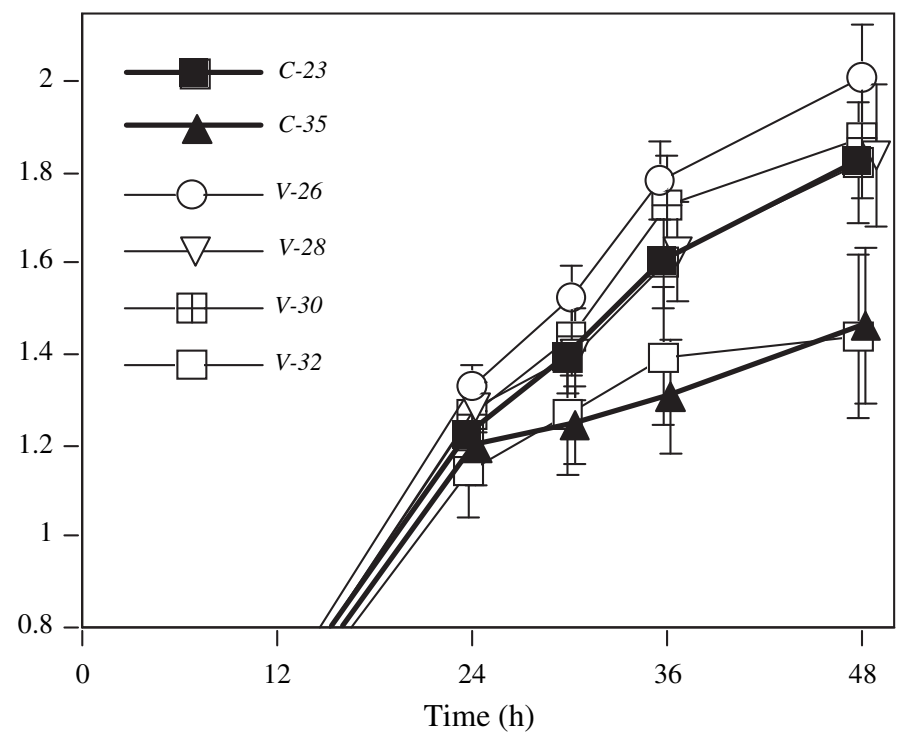

B $35^{\circ} \mathrm{C}$

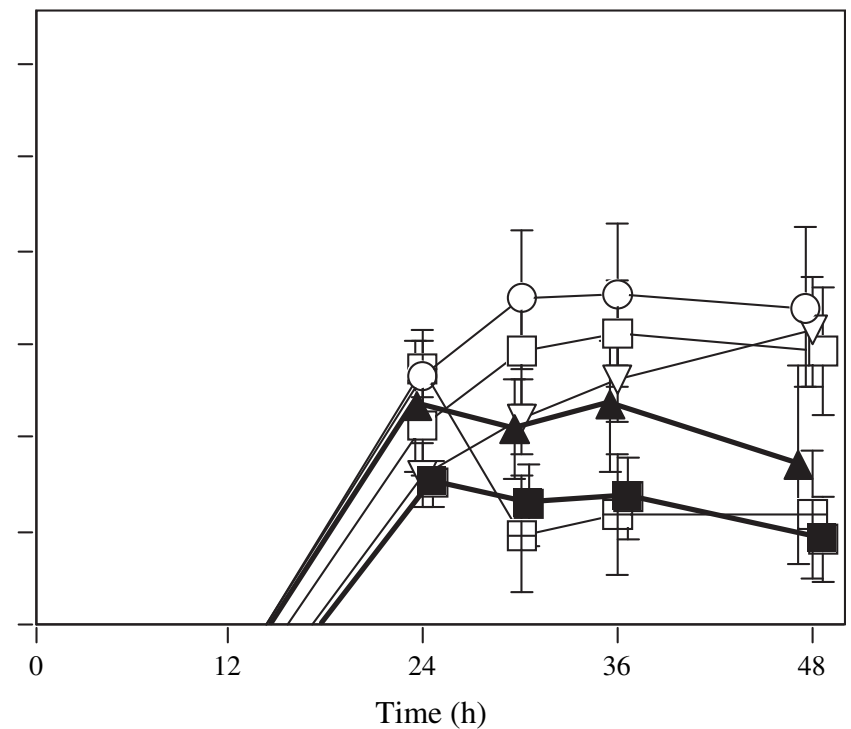

Fig. 1. Changes in mean number of paramecia through time $(24,30,36,48 \mathrm{~h})$, measured at $23{ }^{\circ} \mathrm{C}(\mathrm{A})$ and $35^{\circ} \mathrm{C}(\mathrm{B})$, starting from a single individual. Means shown for 2 constant temperature treatment origins $\left(23{ }^{\circ} \mathrm{C}=C-23 ; 35^{\circ} \mathrm{C}=C\right.$-35) and for 4 variable treatment origins (fluctuating between 23 and $35{ }^{\circ} \mathrm{C}$, with means between 26 and $\left.32{ }^{\circ} \mathrm{C}: \mathrm{V}-26, V-28, V-30, V-32\right)$. Numbers are $\log _{2}$-transformed; thus values $>1$ indicate an increase in number. Error bars denote standard errors. 


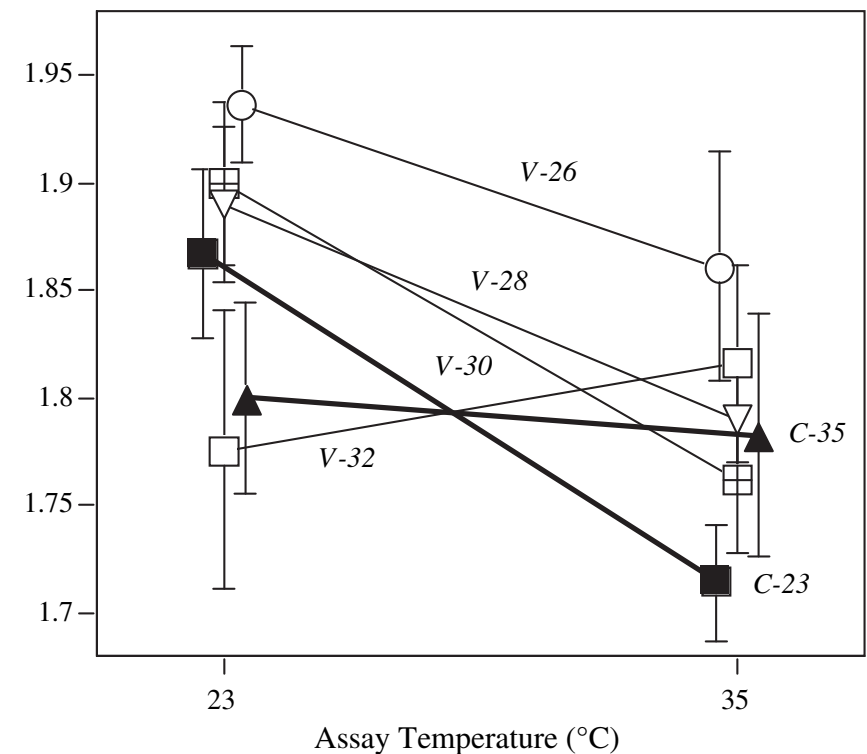

Fig. 2. Mean cumulative paramecium growth over $48 \mathrm{~h}$ at two assay temperatures $\left(23\right.$ and $35^{\circ} \mathrm{C}$ ), as measured by the area under the curve AUC, based on $\log _{2}$-transformed (number of paramecia +1 ). Means shown for 2 constant temperature treatment origins $(C-23, C-35)$ and for 4 variable treatment origins $(V-26, V-28, V-30, V-32)$. Error bars denote standard errors.

particular, the stressful constant $35{ }^{\circ} \mathrm{C}$ environment. One generalist $\left(\mathrm{V} 26\right.$, from a variable treatment with a mean of $\left.26^{\circ} \mathrm{C}\right)$ may even be universally best fit across all environments.

\section{Discussion}

We observed a crossing of reaction norms for Paramecium from the different constant selection treatments when tested at $23{ }^{\circ} \mathrm{C}$ and $35^{\circ} \mathrm{C}$. We will first discuss the implications of these results in terms of evolution of specialists in constant

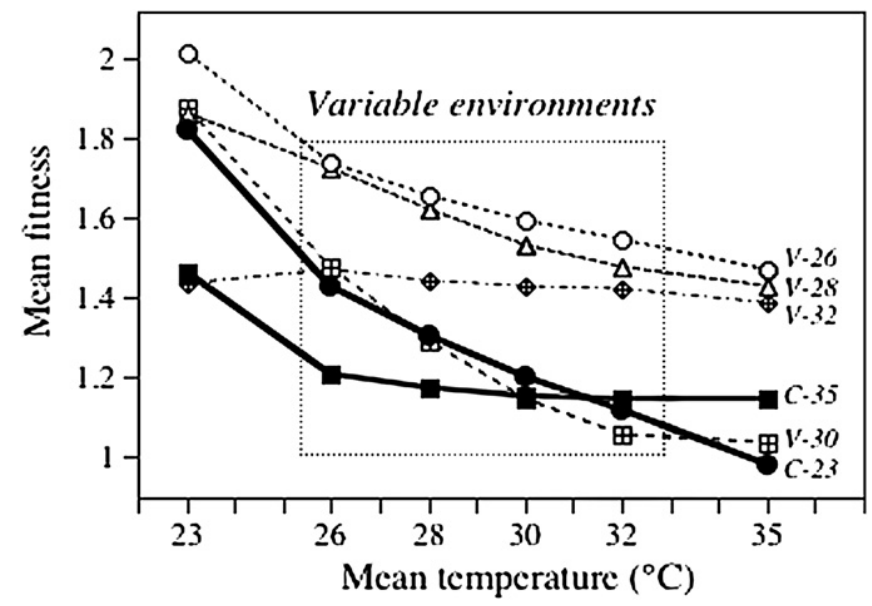

Fig. 3. Mean fitness of constant $(C-23, C-35)$ and variable $(V-26, V-28, V-30$, $V$-32) treatment origins estimated for each of the 4 variable treatment environment temperature means. Fitness was estimated from the mean $\log _{2}$ transformed number of individuals at 23 or $35{ }^{\circ} \mathrm{C}$ after $48 \mathrm{~h}$. For constant environments, fitness is the arithmetic mean at 23 or $35^{\circ} \mathrm{C}$, respectively. For variable environments, geometric means for performance at 23 and $35^{\circ} \mathrm{C}$ were calculated and weighted for the relative frequency of time spent at the two temperatures. environments and then the evolution of generalists in variable environments.

\subsection{Specialisation in constant environments}

Populations from the two constant temperature environments $\left(23{ }^{\circ} \mathrm{C}\right.$ and $\left.35^{\circ} \mathrm{C}\right)$ were observed to have higher levels of division when assayed at their own selection temperature. This finding is consistent with the idea that spatially heterogeneous environments favour the evolution of specialists, each adapted to their own environment (Kawecki and Ebert, 2004). Experimental evolution of specialisation to different (constant) temperature regimes has also been shown, e.g., for the bacterium Escherichia coli and the green alga Chlamydomonas rheinhardtii reviewed in (Kassen, 2002). Although our results are coherent with reciprocal selection in each constant environment, this may not actually be the case. All populations had been cultured at $23{ }^{\circ} \mathrm{C}$ for a number of years prior to the onset of the experiment, such that 4 months of additional selection may not improve fitness at this temperature (see also (Bennett et al., 1992)). Accordingly, the observed crossreaction norms may simply reflect a change in Paramecium cultured under temperature stress $\left(35^{\circ} \mathrm{C}\right)$. Thus, adaptation to $35{ }^{\circ} \mathrm{C}$ apparently comes at a cost whereby populations have reduced performance at $23{ }^{\circ} \mathrm{C}$.

The mechanisms responsible for the observed patterns are not clear. The observed results are coherent with genetic change and evolution occurring in the different populations. Indeed, previous work has indicated a genetic basis of temperature-dependent variation in growth and survival in P. caudatum (Fels and Kaltz, 2006; Duncan et al., 2010). Thus, given the duration of our long-term experiment (4 months), and the population sizes at $35^{\circ} \mathrm{C}(500-1000$ individuals $)$, this is a plausible explanation. However, it is also possible that these results are attributable to acclimation of the Paramecium to the different temperature environments. It is clear, however, from our results, that the $48 \mathrm{~h}$ conditioning period prior to the onset of the experiment did not efface local adaptation in our experiment. Previous work has shown that patterns of acclimation for Paramecium tetraurelia to stressful temperatures $\left(35^{\circ} \mathrm{C}\right.$ as in our experiment) are lost within $24 \mathrm{~h}$ (Hennessey and Nelson, 1979). This result suggests that $48 \mathrm{~h}$ is sufficient to eliminate acclimation and that our results are consistent with evolution. However, another study found that patterns of acclimation for $P$. caudatum between more permissive environments $\left(10^{\circ} \mathrm{C}\right.$ and $\left.25{ }^{\circ} \mathrm{C}\right)$ remained for up to a week (Tsukuda and Takeuchi, 1984). Molecular analysis affirming genetic change in the experiment is required to distinguish between these hypotheses. In addition, true understanding of the mechanisms behind these patterns will require more detailed experiments regarding the time required for acclimation and its subsequent duration.

The responses of Paramecium from the different populations may hint at the underlying physiological mechanisms. At $35{ }^{\circ} \mathrm{C}$, the resident population selected at $35{ }^{\circ} \mathrm{C}$ has a division advantage only during the first $24 \mathrm{~h}$ before division declines at the same rate as Paramecium from $23{ }^{\circ} \mathrm{C}$. This is 
consistent with a constitutive heat stress protection mechanism, such as altered membrane structure (Sasaki et al., 2006). In contrast, at $23{ }^{\circ} \mathrm{C}$, the resident advantage is cumulative, increasing with time, whereas growth from populations originating from $35{ }^{\circ} \mathrm{C}$ increases at first before levelling off. An absence of sustained growth for Paramecium from $35{ }^{\circ} \mathrm{C}$ may be attributable to the cost of the heat-stress protection mechanism when resources (food, oxygen) become limiting in the $60 \mu \mathrm{l}$ drop. Although not expected to serve a constitutive function for heat tolerance, fitness costs of HSP overexpression have been demonstrated in various organisms (Ketola et al., 2004; Sorensen et al., 2003).

\subsection{Evolution of generalists in variable environments}

Our results clearly showed that Paramecium from variable selection environments grow reasonably well at both $23{ }^{\circ} \mathrm{C}$ and $35{ }^{\circ} \mathrm{C}$, consistent with the evolution of a generalist strategy. However, patterns of growth for populations from the different variable treatments were not the same across populations, nor was the performance of these populations intermediate between those of the constant-temperature specialists, as would be expected for typical generalists e.g., (Legros and Koella, 2010). Indeed, environmental variance in growth between the two assay temperatures for populations from variable environments was comparable to that observed for populations from constant environments. This result is inconsistent with the evolution of a bet-hedging strategy predicted for generalists, but consistent with other empirical observations (Leroi et al., 1994; Reboud and Bell, 1997; Kassen and Bell, 1998; Barrett et al., 2005). It seems that generalist evolution here does not select for intermediate fitness across environments encountered, but instead permits optimal adaptation to different components of the environment presented (here: $23{ }^{\circ} \mathrm{C}$ and $35^{\circ} \mathrm{C}$ ).

Further, one novel aspect of our experiment was the use of different types of variable environments, where we manipulated the time that populations spent at $23{ }^{\circ} \mathrm{C}$ and $35{ }^{\circ} \mathrm{C}$. We did not observe that evolution in the performance of Paramecium at the different variable treatments varied in the constant assay environments according to the amount of time they had spent in each. The different relative frequencies of exposure to $35{ }^{\circ} \mathrm{C}$ or $23{ }^{\circ} \mathrm{C}$ had no obvious influence on the order of performance at either assay temperature, nor on the order of the average performance over both temperatures. Combined, these results emphasise an absence of trade-off ensuing different amounts of time spent at each temperature, and no cost for being a generalist in this experiment.

Instead, our results indicate higher fitness of (some) generalists in all variable environments, in particular at increasing mean temperatures, with more frequent exposure to $35^{\circ} \mathrm{C}$. Thus, most variable treatments appear to be better adapted to variable environments than constant treatments (Fig. 3). Moreover, some of the variable treatments produced populations that may even be capable of invading the specialist populations at constant temperatures, especially at $35{ }^{\circ} \mathrm{C}$. In fact, one variable environment (V-26) seems to have generated supergeneralists with over all superior growth at both assay temperatures, and highest projected fitness across all variable mean temperatures (Fig. 3). The absence of a cost for our generalist populations may be attributable to the evolutionary consequences of adapting in a variable environment (Lenormand et al., 2009). Fluctuations in selective pressure can induce "Evolutionary revolutions" sensu Lenormand et al. (2009). That is, when ancestral populations are fixed to a local fitness peak in an adaptive landscape (in our case populations initially adapted to 23C), stochasticity in selection can allow populations to reach a peak higher in the fitness landscape. Here, transient exposure to $35{ }^{\circ} \mathrm{C}$ could help Paramecium find a strategy that was initially worse at $23^{\circ} \mathrm{C}$ but eventually leads to higher fitness at both temperatures. This phenomenon can be compared to "roundabout selection" as exemplified by MacLean et al. (2002).

The physiological mechanism for heat tolerance may not be the same for constant and variable temperature treatments. For example, heat shock proteins are associated with a response that is induced relatively quickly following exposure to heat stress (Feder and Hofmann, 1999) and may not last. Therefore, in temporally variable environments, increased heat stress tolerance may be mediated by selection on the HSP machinery (Ketola et al., 2004). In contrast, constitutive HSP overexpression may be less rewarding under sustained exposure to heat stress, because of the costs associated with it (Sorensen et al., 2003; Ketola et al., 2004). Thus long-term constant exposure to high temperature may even lead to lower HSP expression levels (Cavicchi et al., 1995; Bettencourt et al., 1999). Heat tolerance in our constant $35{ }^{\circ} \mathrm{C}$ treatment may therefore have another mechanistic basis, such as the altered membrane structures mentioned above (Sasaki et al., 2006; Toyoda et al., 2009). The costs associated with each mechanism may be very different, which may explain the different reaction norms for populations from constant and variable environments observed in this experiment. Alternatively, the costs we observe for specialists in foreign environments may arise following mutation accumulation of genes/alleles that are only deleterious in foreign environments (Kassen, 2002). Accumulation of such genes will not occur in variable environments because they will be consistently selected against.

\subsection{Conclusions}

This experiment demonstrates that specialists appear when selection occurs in constant environments, and costs associated with specialisation are consistent with theory. In contrast, evolution under variable conditions produces generalists with often superior fitness at both assay temperatures. Although we cannot be sure, we postulate that there may be different mechanisms mediating heat tolerance for generalists and specialists in our experiment. Constitutive and induced quantification of heat shock protein expression in Paramecium would confirm this hypothesis. Aside from the mechanism, we cannot distinguish whether the phenotypic differences between populations are genetic, or due to trans-generational acclimation. Confirmation of this hypothesis would require 
molecular analysis demonstrating genetic change in populations. Regardless of the mechanism, we demonstrate that patterns of local adaptation unravel differently in constant and variable environments.

\section{Acknowledgements}

We would like to thank two anonymous reviewers for helpful comments on the manuscript. This work was supported by grants from the Université Montpellier 2 (A. B. D.), the Agence National de la Recherche ("ANR-09-BLAN-0099", A. B. D., S. F. and O. K.) and the Centre National de Recherche Scientifique (programme "INSU-EC2CO-Microbien" $\mathrm{N}^{\circ} 125$ to O.K.). This is ISEM contribution 2011-029.

\section{References}

Barrett, R.D., MacLean, R.C., Bell, G., 2005. Experimental evolution of pseudomonas fluorescens in simple and complex environments. Am. Nat. $166,470-480$.

Bell, G., 1997. Selection: The Mechanism of Evolution. Chapman \& Hall, Florence, KY.

Bell, G., 2010. Fluctuating selection: the perpetual renewal of adaptation in variable environments. Phil. Trans. R. Soc. B-Biol. Sci. 365, 87-97.

Bennett, A.F., Lenski, R.E., Mittler, J.E., 1992. Evolutionary adaptation to temperature. I. Fitness responses of Escherichia coli to changes in its thermal environment. Evolution 46, 16-30.

Bettencourt, B.R., Feder, M.E., Cavicchi, S., 1999. Experimental evolution of hsp70 expression and thermotolerance in drosophila melanogaster. Evolution 53, 484-492.

Cavicchi, S., Guerra, D., Latorre, V., Huey, R.B., 1995. Chromosomal analysis of heat-shock tolerance in drosophila-melanogaster evolving at different temperatures in the laboratory. Evolution 49, 676-684.

Duncan, A.B., Fellous, S., Accot, R., Alart, M., Chantung Sobandi, A., Cosiaux, A., Kaltz, O., 2010. Parasite-mediated osmotic stress protection of paramecium caudatum infected by holospora undulata is host genotype specific. FEMS Microbiol. Ecol. 74, 353-360.

Feder, M.E., Hofmann, G.E., 1999. Heat-shock proteins, molecular chaperones, and the stress response: evolutionary and ecological physiology. Ann. Rev. Physiol. 61, 243-282.

Fels, D., Kaltz, O., 2006. Temperature-dependent transmission and latency of holospora undulata, a micronucleus-specific parasite of the ciliate paramecium caudatum. Proc. R. Soc. B-Biol. Sci. 273, 1031-1038.
Hennessey, T., Nelson, D.L., 1979. Thermosensory behavior in parameciumtetraurelia - quantitative assay and some factors that influence thermal avoidance. J. Gen. Microbiol. 112, 337-347.

Jessup, C.M., Kassen, R., Forde, S.E., Kerr, B., Buckling, A., Rainey., P.B., Bohannan, B.J., 2004. Big questions, small worlds: microbial model systems in ecology. Trends Ecol. Evol. 19, 189-197.

Kassen, R., 2002. The experimental evolution of specialists, generalists, and the maintenance of diversity. J. Evol. Biol. 15, 173-190.

Kassen, R., Bell, G., 1998. Experimental evolution in chlamydomonas. Iv. Selection in environments that vary through time at different scales. Heredity 80, 732-741.

Kawecki, T.J., Ebert, D., 2004. Conceptual issues in local adaptation. Ecol Lett. 7, 1225-1241.

Ketola, T., Laakso, J., Kaitala, V., Airaksinen, S., 2004. Evolution of hsp90 expression in tetrahymena thermophila (protozoa, ciliata) populations exposed to thermally variable environments. Evolution 58, 741-748.

Legros, M., Koella, J.C., 2010. Experimental evolution of specialization by a microsporidian parasite. BMC Evol. Biol. 10, 159

Lenormand, T., Roze, D., Rousset, F., 2009. Stochasticity in evolution. Trends Ecol. Evol. 24, 157-165.

Leroi, A.M., Bennett, A.F., Lenski, R.E., 1994. Temperature acclimation and competitive fitness: an experimental test of the beneficial acclimation assumption. Proc. Nat. Acad. Sci. U.S.A 91, 1917-1921.

Levins, R., 1968. Evolution in Changing Environments. Princton University Press, NJ.

MacLean, R.C., Bell, G., 2002. Experimental adaptive radiation in Pseudomonas. Am. Nat. 160, 569-581.

Nidelet, T., 2007. L'effet de la structuration spatiale et de l'hétérogénéité environnementale sur les interactions hôte-parasite: Une approche d'évolution expérimentale et d'épidémiologie. UPMC, Univ Paris.

Reboud, X., Bell, G., 1997. Experimental evolution in chlamydomonas. Iii. Evolution of specialist and generalist types in environments that vary in space and time. Heredity 78, 507-514.

SAS, 2008. Jmp Statistics and Graphics Guide (Version 8.0.1.). SAS Institute, Cary, N.C.

Sasaki, T., Konoha, Y., Toyoda, T., Yasaka, Y., Przybos, E., Nakaoka, Y., 2006. Correlation between thermotolerance and membrane properties in paramecium aurelia. J. Exp. Biol. 209, 3580-3586.

Sorensen, J.G., Kristensen, T.N., Loeschcke, V., 2003. The evolutionary and ecological role of heat shock proteins. Ecol. Lett. 6, 1025-1037.

Stearns, S.C., 2000. Daniel bernoulli (1738): evolution and economics under risk. J. Biosci. 25, 221-228.

Toyoda, T., Hiramatsu, Y., Sasaki, T., Nakaoka, Y., 2009. Thermo-sensitive response based on the membrane fluidity adaptation in paramecium multimicronucleatum. J. Exp. Biol. 212, 2767-2772.

Tsukuda, H., Takeuchi, Y., 1984. Heat-resistance and contractile vacuolar activity of paramecium-caudatum acclimated to different temperatures. Comp. Biochem. Physiol. A-Physiol. 77, 641-645.

Wichterman, R., 1986. The Biology of Paramecium. Plenum Press, New York. 